\title{
Optimization of phenol adsorption onto biochar from oil palm empty fruit bunch (EFB)
}

\author{
Siti Hadjar Md Arshad a, Norzita Ngadi a,*, Syieluing Wong a, Noraishah Saidina Amin a, Fatin \\ Amirah Razmi a, Nurul Balqis Mohamed a, Ibrahim Mohammed Inuwa b, Astimar Abdul Aziz c \\ a Department of Chemical Engineering, Faculty of Chemical and Energy Engineering, Universiti Teknologi Malaysia. \\ ${ }^{b}$ Department of Polymer Engineering, Faculty of Chemical and Energy Engineering, Universiti Teknologi Malaysia 81310 Skudai Johor Bahru \\ Malaysia. \\ c Agro Produk Unit, Stesyen Penyelidikan MPOB-UKM, Malaysia Palm Oil Board (MPOB), Bangi Selangor. \\ * Corresponding author: norzita@cheme.utm.my,
}

\section{Article history}

Received 5 May 2018

Revised 1 June 2018

Accepted 1 July 2018

Published Online 4 February 2019

\begin{abstract}
Malaysia, as one of the leading palm oil producers in the world faces problems in disposal of oil palm empty fruit bunch (EFB), which can be converted into various value-added products, including adsorbents. This study investigated the adsorption of phenol from its solution using biochar produced from EFB through carbonization. Response Surface Methodology (RSM) with Box-Behnken design was used to investigate the effects of three parameters (temperature, time and heating rate) during carbonization on phenol removal by the biochar produced. This was followed by process optimization based on statistical analysis. The results indicated that the optimized carbonization conditions were; $500{ }^{\circ} \mathrm{C}$ for temperature, $10^{\circ} \mathrm{C} / \mathrm{min}$ of heating rate and $80 \mathrm{~min}$ for reaction tim which led to $7.57 \%$ of phenol removal. SEM revealed coarse and uneven surface of the biochar surface, with small degree of pore development. Comparison between FTIR spectrum of EFB and biochar revealed the loss water and hydroxyl compounds from EFB during carbonization. The lack of oxygenated groups (especially carbonyl groups) on the adsorbent surface as well as limited number of pores were the possible reasons leading to low phenol adsorption by biochar, therefore conversion of the biochar to activated carbon was necessary for higher adsorption performance.
\end{abstract}

Keywords: Biochar, adsorption, empty fruit bunch, phenolic compounds, response surface methodology (RSM)

(C) 2019 Penerbit UTM Press. All rights reserved

\section{INTRODUCTION}

Treatment of various contaminants in industrial wastewater has been an important research topic, due to the their deterrent and irreversible effects to human health (S. Wong et al., 2018), Conversion of various biowastes into biochars (Sohaimi et al., 2017), activated carbons (AC) (Md Arshad et al., 2016; Yac'cob et al., 2016), cryogel (Rusli et al., 2016), flocculant (Razak et al., 2016) and biosorbent (Ngadi et al., 2015) for wastewater treatment purpose has been an innovative way to reduce the amount of waste to be sent to landfill or require specialized treatment, as well as the costs of the mentioned materials compared to commercial production sources. In Malaysia, great attention is given to synthesis adsorbents from biowaste generated in palm oil industry, especially empty fruit bunch (EFB). As a main global producer of palm oil, Malaysia generates 16.05 million tonnes of empty fruit bunch (EFB) per annum as agro waste (Anis et al., 2010). When it is handled inappropriately, EFB waste can cause environmental problems, including pollution of soil and water by degradation of chemical compounds contained in EFB (mainly via oxidation). Various processes that can convert EFB into useful products are studied, including biochar that can be used as adsorbent of phenolic compounds in wastewater (Zahangir et al., 2007). Nevertheless, a meta-analysis performed by Alhashimi et al. (2017) indicated that application of biochar could be more environmental friendly than that of activated carbon, due to lower carbon footprint generation during synthesis process . Thus, it is worthy to study the possibility on application of biochar in removal of phenol from simulated wastewater.
As the performance of adsorbents is greatly influenced by several factors during the synthesis process, it is necessary to determine the optimum process conditions in synthesis step of biochar. Such objective can be achieved with the use of Response Surface Methodology (RSM), which is commonly used to study the effects of process variables on the targeted responses in chemical processes (Nabgan et al., 2017; S. L. Wong et al., 2016a) RSM enables the use of experiment design with minimum number of runs (leading to savings in time, materials and hence cost) to obtain reliable statistical data on the process (S. L. Wong et al., 2016b) RSM is also an effective technique in identification of significant factors in complex chemical processes, which enabling in effective optimization of the process (Mohamad et al., 2017). The potential of biochar as adsorbent was also explored by several research teams. Yavari et al. (2017) successfully optimized the biochar production from EFB and rice husk for herbicides removal using Response Surface Methodology (RSM). The factors studied were included temperature $\left(300-700{ }^{\circ} \mathrm{C}\right)$, heating rate $\left(3-10{ }^{\circ} \mathrm{C} / \mathrm{min}\right)$ and retention time (60-180 $\left.\mathrm{min}\right)$. Another research group investigated the influence of temperature (400-700 $\left.{ }^{\circ} \mathrm{C}\right)$, heating rate $\left(5-15^{\circ} \mathrm{C} / \mathrm{min}\right)$ and residence time $(30-180 \mathrm{~min})$ on biochar formation from EFB for removal of $\mathrm{Zn}$ from aqueous solution (Zamani et al., 2017). Experiment design and data analysis using RSM has been applied in many studies. However, optimization in production of biochar from EFB for phenol adsorption is still lacking in the literatures. This study was aimed to investigate the synthesis of biochar from EFB through carbonization in order to remove phenol from simulated wastewater. The effects of several reaction parameters in carbonization, namely temperature, heating rate and time on phenol adsorption by biochar from EFB were studied and optimized. The 
textural properties and surface functional groups of the biochar were also investigated.

\section{MATERIAL AND METHODOLOGY}

\section{Preparation of biochar from empty fruit bunch (EFB) for phenol removal}

The EFB sample was acquired from Malaysia Palm Oil Board (MPOB), while phenol of reagent grade was purchased from Sigma Aldrich. The EFB sample was washed and dried in open air, then crushed and sieved to obtain fibre particles with size greater than 2 $\mathrm{mm}$. For each experiment, the EFB sample was placed in a ceramic tube inside a horizontal tube furnace (CARBOLITE, UK). Purified nitrogen gas $(99.995 \%)$ was flown into the ceramic tube at $1.5 \mathrm{~L} / \mathrm{min}$ for 15 minutes to create an inert environment for carbonization. Thereafter, the EFB sample was carbonized according to the reaction parameters obtained from RSM. Prior to the analysis of phenol removal, the biochar samples were heated overnight at $105{ }^{\circ} \mathrm{C}$ for moisture removal. Each biochar sample, with the mass of $0.05 \mathrm{~g}$, was then mixed with $250 \mathrm{ml}$ of synthetic phenol solution $(0.5 \mathrm{mM})$. Series of conical flasks were then sealed with parafilm and agitated for 6 hours at $41^{\circ} \mathrm{C}$ and 165 revolutions per minute (rpm) to achieve adsorption equilibrium. The final concentration of phenol in each solution was then measured using UV spectrophotometer at $269.0 \mathrm{~nm}$ with the use of standard calibration curve. The percentage of phenol removal in each solution was then calculated according to Equation 1.

$$
\text { Conversion }=\left(C_{0}-C_{t}\right) / C_{0} \times 100 \%
$$

$\begin{array}{lll}\text { Where } & & \\ \mathrm{C}_{0} & = & \text { initial phenol concentration, } \\ \mathrm{C}_{\mathrm{t}} & = & \text { final phenol concentration. }\end{array}$

\section{Design of experiment (DOE)}

According to literature, temperature, heating rate, and time are identified to be the significant factors in carbonization. Thus, RSM was used to determine the significance of these reaction parameters on the response, which was adsorption of phenol from water by the biochar. Optimization of phenol removal was also performed using RSM. Statistica 7 was used to generate Box-Behnken design that contained 17 experiments, each with different levels of reaction parameters. The parameters were coded as $\mathrm{X}_{1}$ (for temperature), $\mathrm{X}_{2}$ (for heating rate) and $X_{3}$ (for time), and their levels were coded as (-1, $0,+1)$. The ranges for each factor, as shown in Table I, were determined based on the previous studies (Acikgoz et al., 2009; Chen et al., 2009; Razuan et al., 2010; Yavari et al., 2017; Zamani et al., 2017), as well as the operational limits of the available equipment in the laboratory. The reaction runs were randomized to minimize the effects of uncontrolled variables (variates).

Table 1 Experimental range and levels coded of independent variables.

\begin{tabular}{ccccc}
\hline & & \multicolumn{3}{c}{ Range and level } \\
\cline { 3 - 5 } Factors & Symbol & -1 & 0 & +1 \\
\hline $\begin{array}{c}\text { Temperature } \\
\left({ }^{\circ} \mathbf{C}\right)\end{array}$ & $X_{1}$ & 500 & 650 & 800 \\
$\begin{array}{c}\text { Heating Rate } \\
\left({ }^{\circ} \mathbf{C} / \text { min) }\right.\end{array}$ & $X_{2}$ & 6.0 & 8.0 & 10.0 \\
Time (min) & $X_{3}$ & 40 & 80 & 120 \\
\hline
\end{tabular}

The phenol removals were fitted in a second order polynomial function to correlate the response with independent variables, as shown in Equation 2 (Zainudin et al., 2005). The application of this function helped to evaluate the linear, quadratic and interactive effects of the independent variables on the dependent variables. One-way ANOVA was used to investigate the significance of different parameters among different sets of biochars. Student's t-test was performed with $\mathrm{p}<0.05$ probability levels.

$$
Y=b_{o}+\sum_{i=1}^{n} b_{i} X_{i}+\left(\sum_{i=1}^{n} b_{i i} X_{i}\right)^{2}+\sum_{i=1}^{n-1} \sum_{j=i+1}^{n} b_{i j} X_{i} X_{j}
$$

where

$\mathrm{Y}=$ predicted response variable,

$b_{0} \quad=$ constant coefficient,

$b_{i} \quad=$ linear coefficient,

$b_{i j}=$ interaction coefficients,

$b_{i i} \quad$ = quadratic coefficient,

$\mathrm{X}_{i}$ and $\mathrm{X}_{j}$ are the independent process variables.

The fitted model was shown in Equation 3.

$$
\begin{aligned}
Y= & b_{0}+b_{1} X_{1}+b_{2} X_{2}+b_{3} X_{3}+b_{11}\left(X_{1}\right)^{2}+b_{22}\left(X_{2}\right)^{2}+b_{33}\left(X_{3}\right)^{2}+ \\
& b_{12} X_{1} X_{2}+b_{13} X_{1} X_{3}+b_{23} X_{2} X_{3}
\end{aligned}
$$

\section{Products characterizations}

The biochar obtained at optimized conditions was characterized. Micromeritics (ASAP 2020) was used for analysis of surface area and pore volume of the biochar. Nitrogen adsorption isotherms with 40point adsorption and desorption at $77 \mathrm{~K}$ was developed on the biochar for further analysis. Brunauer-Emmert-Teller (BET) equation gave the value of specific surface area while t-plot gave the value of micropore volume. Barret-Joyner-Halenda $(\mathrm{BJH})$ model from this analysis gave the understanding on the pore size distribution. The surface morphology of the biochar was examined using a scanning electron microscope (SEM) (Hitachi, S-3400N). Fourier transform infrared analysis (FTIR) was performed using FTIR spectroscope (Perkin Elmer) from wavelengths $650 \mathrm{~cm}^{-1}$ to $4000 \mathrm{~cm}^{-1}$.

\section{RESULTS AND DISCUSSION}

\section{Analysis of adsorption data}

The design matrix for the experiment, together with the predicted and actual response of the study, i.e. phenol removal, weretabulated in Table 2. A Parito plot was constructed to compare the observed values with predicted values for phenol removal, as shown in Fig. 1. The coefficient of determination $\left(\mathrm{R}^{2}\right)$ from the plot was 0.9616 , indicating that $96.16 \%$ of the data variation was accounted by the model. Thus, the model fulfilled the requirement as stated by Haaland (1989) where at least $75 \%$ of the data variability has to be explained by the model. The coefficients of the phenol removal model as proposed in Equation 4 were estimated using multiple regression analysis, and theirvalidities were confirmed using analysis of variance (ANOVA). The analysis, as shown in Table 3, indicated that the F-value of phenol removal was 19.48, which was higher than the tabulated F-value $\left(\mathrm{F}_{0.05,9,7}=3.68\right)$ at significant level of 0.05 . Therefore, the proposed model gave good prediction at high confidence level (95\%). It was noted that the coefficients for quadratic term of temperature, as well as interaction term between temperature and heating time (namely $\mathrm{X}_{1}^{2}$ and $\mathrm{X}_{1} \mathrm{X}_{3}$ respectively) were 0.00004 and -0.00005 , which were too small to be included in Equation 4.

$$
\begin{aligned}
Y= & 32.986-0.05 X_{1}-2.016 X_{2}-0.071 X_{3}+0.170\left(X_{2}\right)^{2}-0.002 X_{1} X_{2}+ \\
& 0.011 X_{2} X_{3}
\end{aligned}
$$


Table 2 Design matrix for Box-Behnken design of three independent variables with the predicted and observed response values.

\begin{tabular}{ccccccccc}
\hline $\begin{array}{l}\text { Run } \\
\text { No. }\end{array}$ & Level & \multicolumn{1}{c}{\begin{tabular}{c} 
Manipulated Variables \\
\cline { 5 - 8 }
\end{tabular}} & & Temperature & $\begin{array}{c}\text { Heating } \\
\text { rate }\end{array}$ & Time & Predicted & Actual \\
\hline $\mathbf{1}$ & 1 & 1 & 0 & 800 & 6 & 80 & 0.96 & 1.17 \\
$\mathbf{2}$ & 1 & -1 & 0 & 500 & 6 & 80 & 4.60 & 5.07 \\
$\mathbf{3}$ & 0 & 1 & -1 & 650 & 8 & 80 & 2.12 & 2.21 \\
$\mathbf{4}$ & 0 & 0 & 0 & 500 & 10 & 80 & 7.58 & 7.37 \\
$\mathbf{5}$ & 0 & -1 & -1 & 650 & 8 & 80 & 2.12 & 2.67 \\
$\mathbf{6}$ & 1 & 0 & 1 & 800 & 8 & 120 & 0.97 & 1.12 \\
$\mathbf{7}$ & -1 & 0 & 1 & 650 & 6 & 120 & 1.47 & 1.11 \\
$\mathbf{8}$ & 0 & 0 & 0 & 650 & 8 & 80 & 2.12 & 2.62 \\
$\mathbf{9}$ & 0 & 0 & 0 & 800 & 8 & 40 & 0.97 & 1.08 \\
$\mathbf{1 0}$ & 0 & 0 & 0 & 650 & 10 & 40 & 2.80 & 3.16 \\
$\mathbf{1 1}$ & 1 & 0 & -1 & 650 & 6 & 40 & 2.64 & 2.32 \\
$\mathbf{1 2}$ & -1 & 1 & 0 & 650 & 8 & 80 & 2.12 & 1.2 \\
$\mathbf{1 3}$ & 0 & 0 & 0 & 500 & 8 & 40 & 5.01 & 4.86 \\
$\mathbf{1 4}$ & -1 & -1 & 0 & 650 & 10 & 120 & 5.21 & 5.53 \\
$\mathbf{1 5}$ & 0 & 0 & 0 & 650 & 8 & 80 & 2.12 & 1.89 \\
$\mathbf{1 6}$ & 0 & 1 & 1 & 800 & 10 & 80 & 1.88 & 1.41 \\
$\mathbf{1 7}$ & -1 & 0 & -1 & 500 & 8 & 120 & 6.27 & 6.16 \\
\hline
\end{tabular}

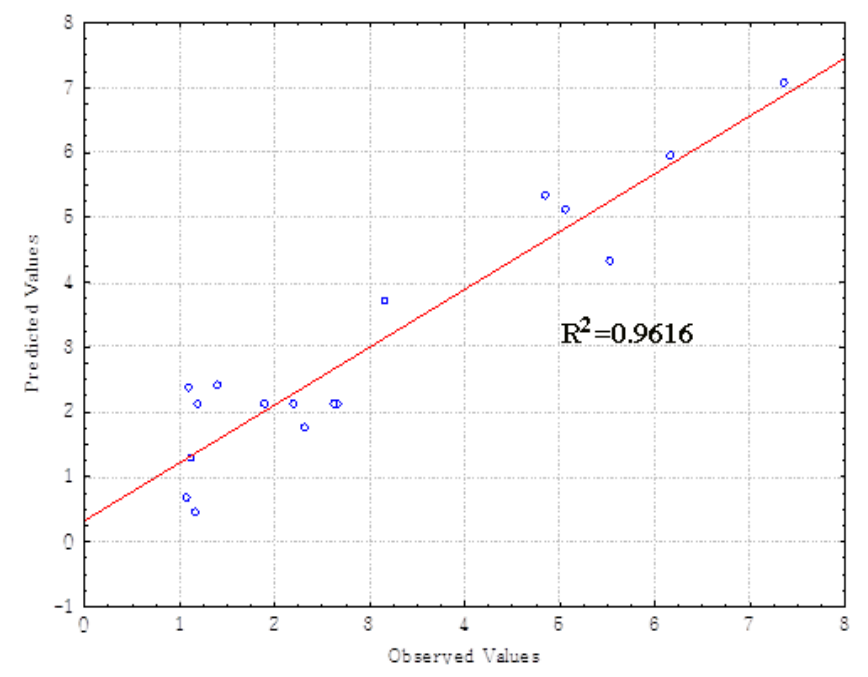

Fig. 1 Parito plot for phenol removal.

Table 3. ANOVA of quadratic model for phenol removal.

\begin{tabular}{llllll}
\hline Sources & $\begin{array}{c}\text { Sum of } \\
\text { Squares } \\
\text { (SS) }\end{array}$ & $\begin{array}{c}\text { Degree } \\
\text { of } \\
\text { Freedom } \\
\text { (d.f) }\end{array}$ & $\begin{array}{c}\text { Mean } \\
\text { Squares } \\
\text { (MS) }\end{array}$ & $\begin{array}{c}\text { F- } \\
\text { value }\end{array}$ & Fon $_{\mathbf{0 . 0 5}}$ \\
\hline $\begin{array}{l}\text { Regression } \\
\text { (SSR) }\end{array}$ & 63.21 & 9 & 7.02 & 19.48 & $>3.68$ \\
$\begin{array}{l}\text { Residual } \\
\text { Total } \\
\text { (SST) }\end{array}$ & 2.52 & 7 & 0.36 & & \\
\hline
\end{tabular}

In order to visualize the contribution of each factor, as well as their interactions, on phenol removal, a Pareto chart was produced together with the student's t-distribution values and p-values of each term in Equation 4. A smaller p-value (below 0.05) and greater t-value indicated that the term was more significant in the model. According to Fig. 2, linear term associated with reaction temperature $\left(\mathrm{X}_{1}\right)$ exerted the greatest effect on phenol removal, with the t-value of -10.999 and p-value of 0.000 . This was followed by linear term of heating rate $\left(\mathrm{X}_{2}\right)$, quadratic term of reaction temperature $\left(\mathrm{X}_{1}^{2}\right)$, interaction between the linear terms of heating rate and reaction time $\left(\mathrm{X}_{2} \mathrm{X}_{3}\right)$ and quadratic term of heating rate $\left(X_{2}^{2}\right)$. All the values were taken at $97 \%$ significant level.

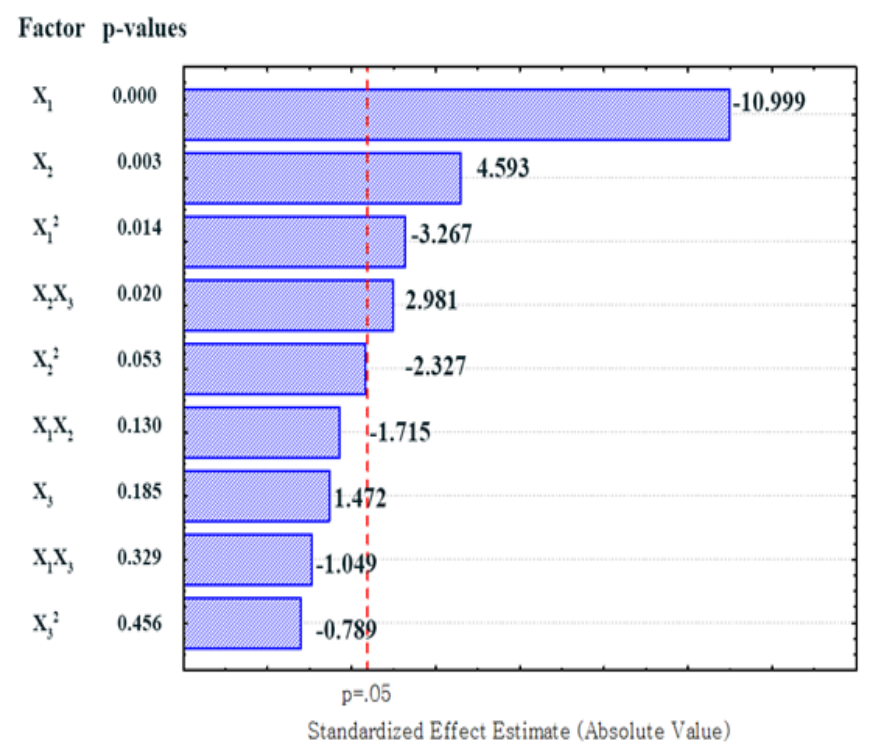

Fig. 2 Pareto chart for phenol removal.

\section{Effect of Different Factors on the Phenol Removal}

Three-dimensional surfaces were plotted within the experimental range to show the effect of each factor, together with interaction effects between different factors, as shown in Fig. 3. In general, the phenol removal was increased when the carbonization temperature was lowered, as the EFB was transformed into non-graphitizable carbon during the process. Thus, low heat treatment was necessary in order to produce biochar with porous structure (Marsh et al., 2006). It was also found that phenol removal was increased along with the increasing of heating rate. However, the value was considered low compared to the range under study. In this range, volatile materials that contained heavy compounds with high $\mathrm{C} / \mathrm{H}$ ratio have more time to repolymerize inside the activated carbon, thus leading to formation of tailored mesopores in the activated carbon (Asadullah et al., 2010). Greater amount of carbon with better pore-structure had tendency to adsorb more adsorbate, thus enhanced the phenol removal. On the other hand, reaction time has little effect on phenol removal. The interaction between different factors can be determined by observing their corresponding contour plots under the response surfaces. The elliptical nature of contour plot shown in Fig. 3(a) indicated that interaction between time and heating rate produced significant effect on phenol removal. On the other hand, the circular nature of contour plots as shown in Fig. 3(b) and 3(c) indicated that the interaction between time and temperature, as well as that between temperature and heating rate did not produce significant effect on phenol removal.

The critical point found from the result of this study was a minimum point. However, it was desired to obtain reaction conditions within the ranges that could produce biochar with maximum phenol removal. Therefore, the reaction condition that could produce such result in the runs was used. Additional run on carbonization of EFB was performed with the reaction conditions as stated in Table 4, and the comparison was made between predicted and observed phenol removal. The deviation between the former and latter was $-2.51 \%$, thus the optimum condition to produce highest phenol removal was at temperature of $500^{\circ} \mathrm{C}$, heating rate of $10^{\circ} \mathrm{C} / \mathrm{min}$ and heating time of $80.27 \mathrm{~min}$. However, the phenol adsorption capacity was still low compared to most adsorbents reported in literature, thus it was 
necessary to investigate the adsorption performance of EFB-AC produced from activation of the biochar.

(a)

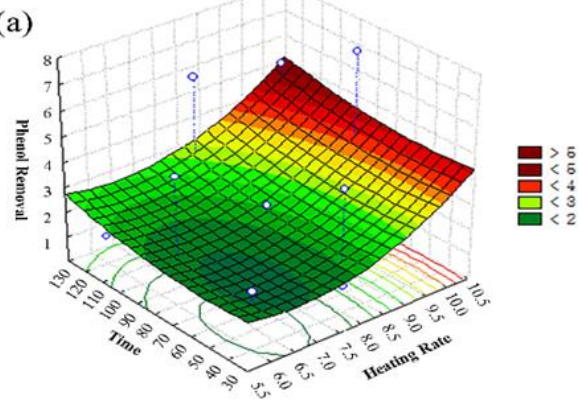

(b)

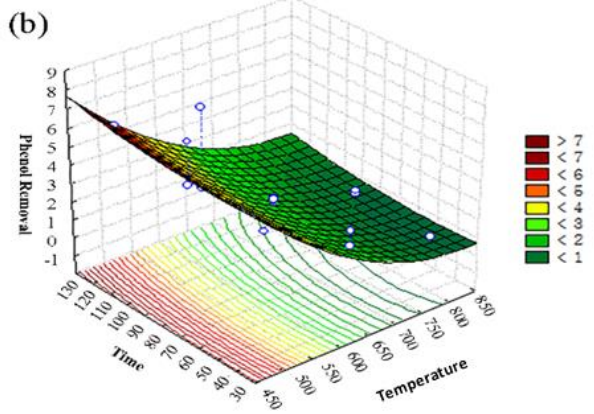

(c)

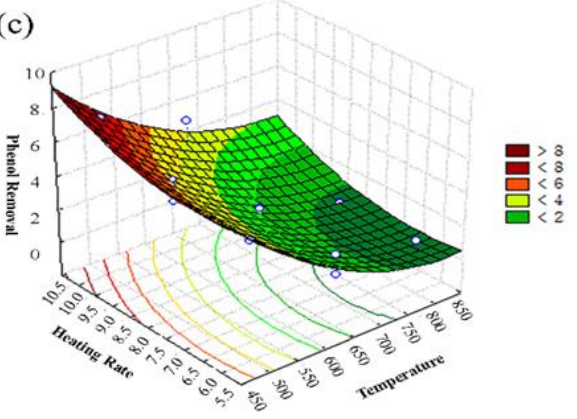

Fig. 3 Surface plots of the combined (a) time and heating rate, (b) time and temperature, and (c) heating rate and temperature on the phenol removal.

Table 4 Comparison between predicted and observed response at the optimum condition obtained from RSM.

\begin{tabular}{ccccc}
\hline Temperature & $\begin{array}{c}\text { Heating } \\
\text { rate }\end{array}$ & $\begin{array}{c}\text { Reaction } \\
\text { time }\end{array}$ & Predicted & $\begin{array}{c}\text { Observed } \\
\text { phenol } \\
\text { removal }\end{array}$ \\
\hline $500^{\circ} \mathrm{C}$ & $10^{\circ} \mathrm{C} / \mathrm{min}$ & $80.27 \mathrm{~min}$ & $7.57 \%$ & $7.38 \%$ \\
\hline
\end{tabular}

\section{Characterization of biochar}

The surface morphology of the optimized biochar was shown in Fig. 4. The biochar surface was coarse, uneven, and swelling. Pore development was also observed on the biochar, but only to a small extent. The morphology of the biochar obtained in this study was similar to the biochar synthesized from EFB by Samsuri et al. (2013). The BET surface area and average pore diameter of the optimized biochar were $21.9 \mathrm{~m}^{2} / \mathrm{g}$ and $24.2 \AA$ respectively. Such values indicat the limited pore development during carbonization stage. The result was in agreement with the work done by Chen et al. (2009), which revealed that the orange peels based biochar carbonized at different temperatures (i.e $150{ }^{\circ} \mathrm{C}$ to $500{ }^{\circ} \mathrm{C}$ ) for 6 hours possessed BET surface area in the range of $7.75-42.40 \mathrm{~m}^{2} / \mathrm{g}$. Meanwhile, the optimized biochar produced in this study had total pore volume of $0.013 \mathrm{~cm}^{3} / \mathrm{g}$ and average pore width of $2.4 \mathrm{~nm}$. Thus, filling of biochar pores by phenol was feasible, as the molecules could penetrate pores that bigger than $1 \mathrm{~nm}$. Nevertheless, the low phenol adsorption by biochar suggested that pore filling was less significant in the process, most probably due to the limited number of pores as indicated by small pore volume.

Chemical interaction between phenol molecules and biochar surface functional groups is another important factor in adsorption. The FTIR spectra for EFB and the optimized biochar were shown in Fig. 5, and the major bands identified for these two compounds were listed in Table V. All functional groups including $\mathrm{O}-\mathrm{H} / \mathrm{N}-\mathrm{H}, \mathrm{C}-\mathrm{H}$, $\mathrm{C}=\mathrm{O}, \mathrm{C}=\mathrm{C}, \mathrm{C}-\mathrm{H}, \mathrm{C}-\mathrm{O}, \mathrm{C}=\mathrm{N}$ and $\mathrm{C}-\mathrm{H}$ could be observed in raw EFB. However, disappearance of some functional groups after carbonization, including $\mathrm{O}-\mathrm{H} / \mathrm{N}-\mathrm{H}, \mathrm{C}-\mathrm{O}$ and $\mathrm{C}=\mathrm{O}$ groups could be observed from the figure. A band number between 1675 and $1575 \mathrm{~cm}^{-}$ ${ }^{1}$ as well as between 1460 and $1350 \mathrm{~cm}^{-1}$ which were assigned to $\mathrm{C}=\mathrm{C}$ and $\mathrm{C}-\mathrm{H}$ stretchings, respectively, were detected in both raw EFB and optimized biochar. The low band between 900 and $650 \mathrm{~cm}^{-1}$ were detected in both samples which were assigned to $\mathrm{C}-\mathrm{H}$ bending in aromatic compounds. The lack of oxygenated groups in biochar was disadvantageous to phenol adsorption, which was believed to take place via donor-acceptor complex mechanism between the carbonyl groups and phenol's aromatic ring (Mattson et al., 1969). In short, the textural properties and surface chemistry of the biochar was less favourable for phenol adsorption, hence it was necessary to convert the biochar to activated carbon for higher adsorption performance.

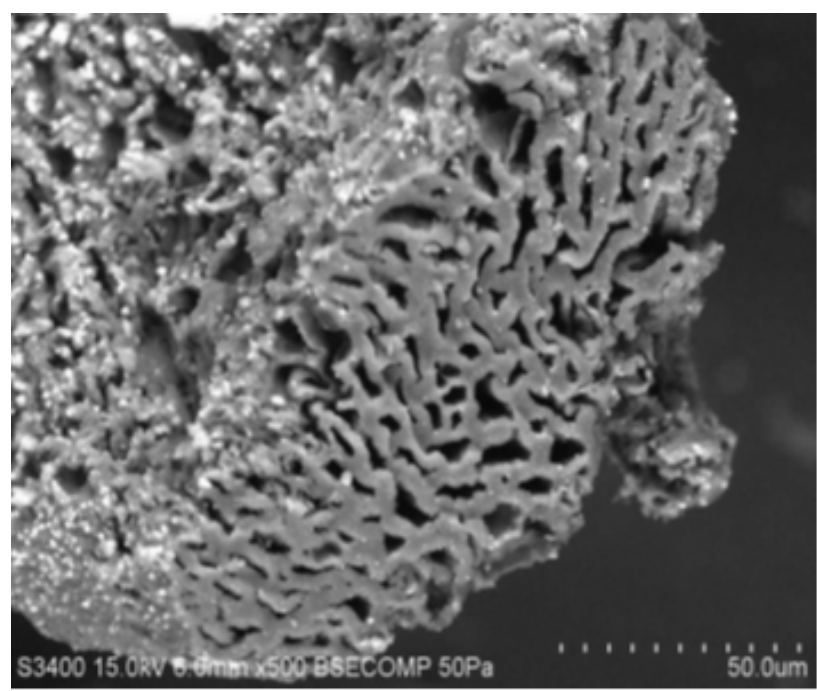

Fig. 4 SEM micrograph of biochar $\left(500^{\circ} \mathrm{C}, 10^{\circ} \mathrm{C} / \mathrm{min}, 0.3 \mathrm{~min}\right)(500 \mathrm{x})$.

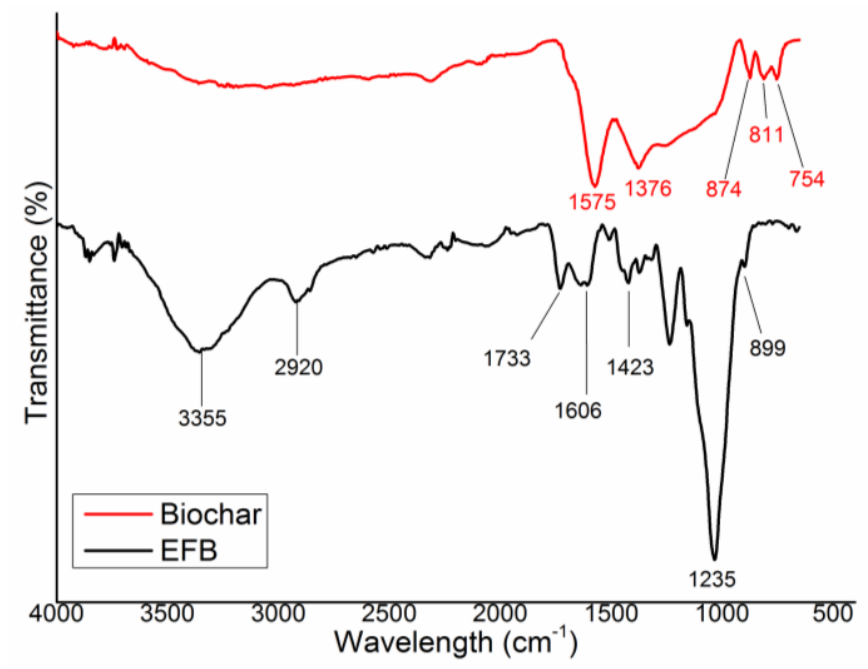

Fig. 5 FTIR spectrum of EFB and biochar. 
Table 5 Functional groups of EFB and biochar according to FTIR Spectrum

\begin{tabular}{ll}
\hline FTIR spectra & Corresponding functional groups \\
\hline EFB & \\
3355 & O-H stretching, N-H stretching \\
2920 & C-H stretching \\
1733 & C=O stretching \\
1606 & C=C stretching, C=N stretching \\
$1423-1378$ & C-H stretching \\
$1235-1034$ & C-O stretching \\
$899-665$ & C-H bending \\
\hline
\end{tabular}

\begin{tabular}{ll}
\hline Biochar & \\
1575 & C=C stretching \\
1376 & C-H stretching \\
874 & C-H bending \\
811 & C-H bending \\
754 & C-H bending \\
\hline
\end{tabular}

\section{CONCLUSION}

The effects of carbonization process parameters of temperature, heating rate and carbonization time on removal of phenol were studied by application of Box-Behnken design. Temperature was found to exhibit the most significant effect on phenol removal. The best phenol removal was obtained at $500{ }^{\circ} \mathrm{C}, 10^{\circ} \mathrm{C} / \mathrm{min}$ and $80 \mathrm{~min}$ resulting in $7.57 \%$ removal. This experimental value was in agreement of predicted value by the model with deviation errors of $3.59 \%$. The BET surface area of biochar produced at optimum conditions was $21.9 \mathrm{~m}^{2}$, total pore volume of $0.013 \mathrm{~cm}^{3} / \mathrm{g}$ and average pore width of $2.4 \mathrm{~nm}$. The morphology of biochar was consisted of irregular pore size distribution and pore arrangement. FTIR spectrum illustrated deduction in a few functional groups in biochar after EFB was carbonized at optimum conditions. The characterization results indicated less favourable conditions for adsorption of phenol onto the biochar, thus it was necessary to determine the performance of $\mathrm{AC}$ produced by activation of the biochar.

\section{ACKNOWLEDGEMENT}

The authors acknowledge the research fellowship provided by Malaysia Palm Oil Board (MPOB) under the Graduate Student Assistantship Scheme (GSAS) and to the Ministry of Higher Education Malaysia (MOHE) for the financial in the form of Fundamental Research Grant Scheme (Vot no. 4F872).

\section{REFERENCES}

Acikgoz, C., Kockar, O. M. 2009. Characterization of slow pyrolysis oil obtained from linseed (Linum usitatissimum L.). Journal of Analytical and Applied Pyrolysis, 85, 151-154.

Alhashimi, H. A., Aktas, C. B. 2017. Life cycle environmental and economic performance of biochar compared with activated carbon: A meta-analysis. Resources Conservation and Recycling, 118, 13-26.

Anis, M., Kamarudin, H., Astimar, A. 2010. Oil palm biomass: Supply and new potential products. Proceedings of the Seminar on Biomass for Biofuels and Value-Added Products 2009: Towards Efficient Utilization of Biomass. 27-28 October. Kuala Lumpur: Institut Penyelidikan Perhutanan Malaysia.
Asadullah, M., Zhang, S., Li, C. Z. 2010. Evaluation of structural features of chars from pyrolysis of biomass of different particle sizes. Fuel Process. Technology, 91, 877-881.

Chen, B., Chen, Z. 2009. Sorption of naphthalene and 1-naphthol by biochars of orange peels with different pyrolytic temperatures. Chemosphere, 76, 127-133.

Haaland, P. D. 1989. Experimental Design in Biotechnology (Vol. 105). New York: CRC press.

Marsh, H., Reinoso, F. R. 2006. Activated Carbon. United Kingdom: Elsevier.

Mattson, J. A., Mark, H. B., Malbin, M. D., Weber, W. J., Crittenden, J. C. 1969. Surface chemistry of active carbon: Specific adsorption of phenols. Journal of Colloid and Interface Science, 31, 116-130.

Md Arshad, S. H., Ngadi, N., Aziz, A. A., Amin, N. S., Jusoh, M., Wong, S. 2016. Preparation of activated carbon from empty fruit bunch for hydrogen storage. Journal of Energy Storage, 8, 257-261.

Mohamad, M., Ngadi, N., Wong, S. L., Jusoh, M., Yahya, N. Y. 2017. Prediction of biodiesel yield during transesterification process using response surface methodology. Fuel, 190, 104-112.

Nabgan, B., Nabgan, W., Tuan Abdullah, T. A., Tahir, M., Gambo, Y., Ibrahim, M., Syie Luing, W. 2017. Parametric study on the steam reforming of phenol-PET solution to hydrogen production over $\mathrm{Ni}$ promoted on $\mathrm{Al} 2 \mathrm{O} 3$-La $2 \mathrm{O} 3$ catalyst. Energy Conversion and Management, 142, 127-142.

Ngadi, N., Rzmi, F. A., Alias, H., Rahman, R. A., Jusoh, M. 2015. Biosorption of removal heavy metal using hybrid Chitosan-Pandan. Advances in Environmental Biology, 9, 30-36.

Razak, M., Fatimah, S., Ngadi, N., Arsad, N. J. 2016. Cellulose-g-PAM derived from kenaf for ethyl orange removal. Applied Mechanics and Materials, 818, 246-249.

Razuan, R., Chen, Q., Zhang, X., Sharifi, V., Swithenbank, J. 2010. Pyrolysis and combustion of oil palm stone and palm kernel cake in fixed-bed reactors. Bioresource Technology, 101, 4622-4629.

Rusli, N. S., Ngadi, N. 2016. Adsorptive removal of chromium (VI) ions using cryogel derived from oil palm fronds' lignin. Applied Mechanics and Materials, 818, 237-241.

Samsuri, A. W., Sadegh-Zadeh, F., Seh-Bardan, B. J. 2013. Adsorption of $\mathrm{As}(\mathrm{III})$ and $\mathrm{As}(\mathrm{V})$ by Fe coated biochars and biochars produced from empty fruit bunch and rice husk. Journal of Environmental Chemical Engineering, 1, 981-988.

Sohaimi, K. S. A., Ngadi, N., Mat, H., Inuwa, I. M., Wong, S. 2017. Synthesis, characterization and application of textile sludge biochars for oil removal. Journal of Environmental Chemical Engineering, 5, 1415-1422.

Wong, S., Ngadi, N., Inuwa, I. M., Hassan, O. 2018. Recent advances in applications of activated carbon from biowaste for wastewater treatment: A short review. Journal of Cleaner Production, 175, 361-375.

Wong, S. L., Abdullah, T. A. T., Ngadi, N., Ahmad, A., Inuwa, I. M. 2016 a. Parametric study on catalytic cracking of LDPE to liquid fuel over ZSM-5 zeolite. Energy Conversion and Management, 122, 428-438.

Wong, S. L., Ngadi, N., Amin, N. A., Abdullah, T. A., Inuwa, I. M. 2016b. Pyrolysis of low density polyethylene waste in subcritical water optimized by response surface methodology. Environmental Technology, 37, 245254.

Yac'cob, N., Atiqah, N., Ngadi, N., Abd Rahman, R. 2016. Preparation and characterization of textile sludge-based activated carbon for dyes removal. Applied Mechanics and Materials, 818, 250-253.

Yavari, S., Malakahmad, A., Sapari, N. B., Yavari, S. 2017. Synthesis optimization of oil palm empty fruit bunch and rice husk biochars for removal of imazapic and imazapyr herbicides. Journal of Environmental Economics and Management, 193, 201-210.

Zahangir, A., Muyibi, S. A., Toramae, J. 2007. Statistical optimization of adsorption processes for removal of 2, 4-dichlorophenol by activated carbon derived from oil palm empty fruit bunches. Journal of Environmental Sciences, 19, 674-677.

Zainudin, N. F., Lee, K. T., Kamaruddin, A. H., Bhatia, S., Mohamed, A. R. 2005. Study of adsorbent prepared from oil palm ash (OPA) for flue gas desulfurization. Separation and Purification Technology, 45, 50-60.

Zamani, S. A., Yunus, R., Samsuri, A. W., Salleh, M. A. M., Asady, B. 2017. Removal of Zinc from aqueous solution by optimized oil palm empty Fruit bunches biochar as low cost adsorbent. Bioinorganic Chemistry and Applications, 2017, 7914714. 